\title{
The Phenology of Infestations and the Impacts of Different Varieties of Cold Hardy Red Raspberries on Drosophila suzukii
}

\author{
Grace F. H. Sward, Sydney E. Glass, Christopher R. Philips \\ Department of Entomology, University of Minnesota, North Central Research \& Outreach Center, \\ Grand Rapids, MN, USA \\ Email: cphilips@umn.edu
}

Received 14 June 2016; accepted 23 July 2016; published 26 July 2016

Copyright (C) 2016 by authors and Scientific Research Publishing Inc.

This work is licensed under the Creative Commons Attribution International License (CC BY).

http://creativecommons.org/licenses/by/4.0/

(c) (i) Open Access

\begin{abstract}
Spotted wing drosophila, Drosophila suzukii (Matsumura) (SWD), is emerging as the most significant pest of berries and stone fruits worldwide. With a broad host range, thin-skinned berries are particularly susceptible to infestation, and fruit producers are desperate for methods to control this pest. One of the keys to developing an integrated management program for SWD is to understand host preference and varietal susceptibility of highly susceptible crop hosts. Working in replicated small plots, experiments were conducted to evaluate differences in varietal susceptibility on cold hardy red primocane fruiting raspberries. Significant differences were observed in both the level of infestation and in the average number of larvae per berry by variety. In addition, it appears that there is a significant negative correlation between the level of infestation and the number of larvae per fruit with the time of sampling, but only an interaction of variety and time for the number of larvae per berry. These data provide a better understanding of the biology and ecology of this pest which is critical in refining current management practices. Knowledge of these interactions can aid in optimizing control strategies such as fine-tuning spatial and temporal control measures, which may be particularly important for early season infestations.
\end{abstract}

\section{Keywords}

Drosophila, Drosophila suzukii, Integrated Pest Management, Raspberries

\section{Introduction}

Spotted wing drosophila, Drosophila suzukii (Matsumura) (SWD), is a significant worldwide pest of berries and 
stone fruits, with both its infestations and adverse economic effects being reported across the globe [1]-[5]. Unlike most Drosophila species, SWD females oviposit primarily in ripening fruits, presenting a major threat to U.S. fruit industries. Since its first detection in California during the 2008 growing season, SWD has spread throughout the U.S. causing significant yield losses, often reaching 100\%. Current SWD management consists of insecticide applications on a four to five-day schedule. Increased chemical inputs add substantial new costs to growing operations and increased risks to surrounding ecosystems, leading to numerous growers abandoning these crops, and substantial economic losses. These dramatic increases in pesticide use with combined yield losses are leading to estimated cost approaching $\$ 1$ billion annually [1] [6]-[9].

Drosophila suzukii possesses a broad host range, with thin-skinned berries (e.g., caneberries, blueberries, strawberries) and stone fruits (e.g., cherries, peaches, plums) being particularly susceptible to infestation [10]. In Japan, where SWD biology has been studied since the 1930s, Kanzawa [11] reported SWD-related damage on various fruit crops with subsequent authors reporting its occurrence on various wild fruits as well [12]-[14]. In the US, raspberries appear to be particularly preferred hosts for SWD [9], while some other small fruits, are only suitable when damaged [15].

Successful integrated pest management (IPM) is dependent on understanding where and when pests occur before taking action. However, a major challenge with the rapids arrival of invasive species such as SWD is our lack of fundamental knowledge about their biology and ecology. Without a firm understanding of some of these basic questions including potential geographic range and invasiveness management attempts are likely to fail [16]. Recurring questions from fruit growers include how, where and when cultural or chemical control methods should be applied. A better understanding of the biology and ecology of this species is critical in refining current management practices for this pest. Spatial optimization of control may be particularly important when early season infestations are likely to occur due to the emigration of overwintering individuals from other areas [14] [17] [18]. Dispersal and movement from crop and non-crop hosts remains one of the most challenging variables to characterize, particularly for insects of small size in natural settings [9] [16] [19]-[21]. Nevertheless, it is also one of the more important variables in designing monitoring and control programs for invasive pests.

One of the keys to development of an IPM program for SWD remains understanding host preference and varietal susceptibility of preferred host crops. Currently, there is little information on the susceptibility of cold hardy berry varieties or the potential to use plant phenology as a cultural control for SWD infestations. In addition, the limited information that is available on SWD management is based on studies from other regions with drastically different climates [14] [20]. If specific mechanisms on host use and varietal susceptibility as well as plant-insect phenology can be identified, documented, and disseminated, we can provide berry producers with methods to continue sustainable production and maintain profitability. Selecting varieties that provide a phenological mismatch with key pests is an environmentally-sound approach, providing growers with a significant and sustainable improvement over the frequent use of insecticide applications currently recommended. Therefore, we evaluated susceptibility of six varieties of cold hardy raspberries to SWD over two years. Given its high potential for rapid spread and economic impact, it is imperative that we improve our understanding of the underlying processes that shape SWD distributions.

\section{Materials and Methods}

\subsection{Infestation Rates}

The potential differences in $D$. suzukii infestation rates between species and varieties within species were measured from 2014 to 2015 at the North Central Research and Outreach Center in Grand Rapids, MN. A total of six varieties (Table 1) grown in a replicated trial established in 2010 were observed on one sample date in 2014 and

Table 1. Berry quality ratings for varieties of Red Primocane-Fruiting raspberries evaluated for spotted-wing drosophila infestations in 2014 and 2015.

\begin{tabular}{|c|c|c|c|c|c|c|c|c|}
\hline Variety & Hardiness & Harvest & Productivity & Fruit Size & Attractiveness & Firmness & Flavor & Freezing \\
\hline Autumn Bliss & fair & early & very good & large & very good & good & very good & very good \\
\hline Polana & good & early & excellent & medium & very good & fair & fair & good \\
\hline Autumn Britten & fair & early & good & large & very good & very good & excellent & good \\
\hline Caroline & fair & mid late & good & large & very good & good & very good & good \\
\hline Joan J & excellent & mid & very good & large & excellent & very good & very good & very good \\
\hline
\end{tabular}


12 sample dates each in 2015. The 2014 sample was collected on 9 September, and in 2015, samples were collected throughout the fruiting period, beginning on 10 August and ending on 28 August. Varieties were replicated in four blocks and a between three and ten fruit, depending on availability, were collected per plot at each harvest from each variety.

Following collection, samples were placed in 30-ml to 89-ml plastic cups (Dart Container Corporation, Mason, MI, 48854) depending on fruit size. Cups were sealed with a screened lid to reduce fungal growth. In some cases, a small cotton swab or sand layer was added to the bottom of the container to absorb moisture. Cups were placed in the laboratory at approximately $21^{\circ} \mathrm{C} \pm 1{ }^{\circ} \mathrm{C}$. Fruit were immediately placed individually in a sugar water solution [22] and macerated. The percent of fruit with emerging D. suzukii ([number of infested fruit/total number of fruit] $\times 100$ ) and the total number of larvae present were recorded.

\subsection{Abundance and Damage}

Data on larval abundance and percent damaged fruit were analyzed using the general linear hypothesis within the mixed model ANOVA framework, correcting for heteroscedasticity as necessary for lack of normality using JMP ${ }^{\circledR}$, Pro 11(SAS Institute Inc., Cary, NC, 1989-2007) [23]. The model included the factors: variety, sample date (time), and the variety $\mathrm{x}$ time interaction. If no interaction was determined, a one-way analysis of variance with a Tukey's HSD at the $p<0.05$ level of significance was used to separate differences in means. The relationship between the number of larvae present and the percent of infested fruit were examined using correlation in JMP ${ }^{\circledR}$, Pro 11(SAS Institute Inc., Cary, NC, 1989-2007). Variables for these analysis consisted of the total larval abundance per fruit and the average percent of damaged fruit and the date the sample was collected. Analyses were performed on data from both in 2014 and 2015.

\section{Results}

\subsection{Infestation Rates}

Plant variety did significantly alter the percent of infested fruit $(\mathrm{F}=5,76=36.67 p<0.0001$; Figure 1 ) as did the time of sample $(\mathrm{F}=1,76=3.39 p<0.0081)$, but there was no interaction between variety and time $(\mathrm{F}=5$, $76=1.75 p<0.134)$. There was a significant negative correlation between the percent of infested fruit and sample date $\mathrm{F}=1,86=42.71 p<0.001 ; \mathrm{r}^{2}=0.33$ ) with significantly fewer berries infested with later samples (Figure 2).

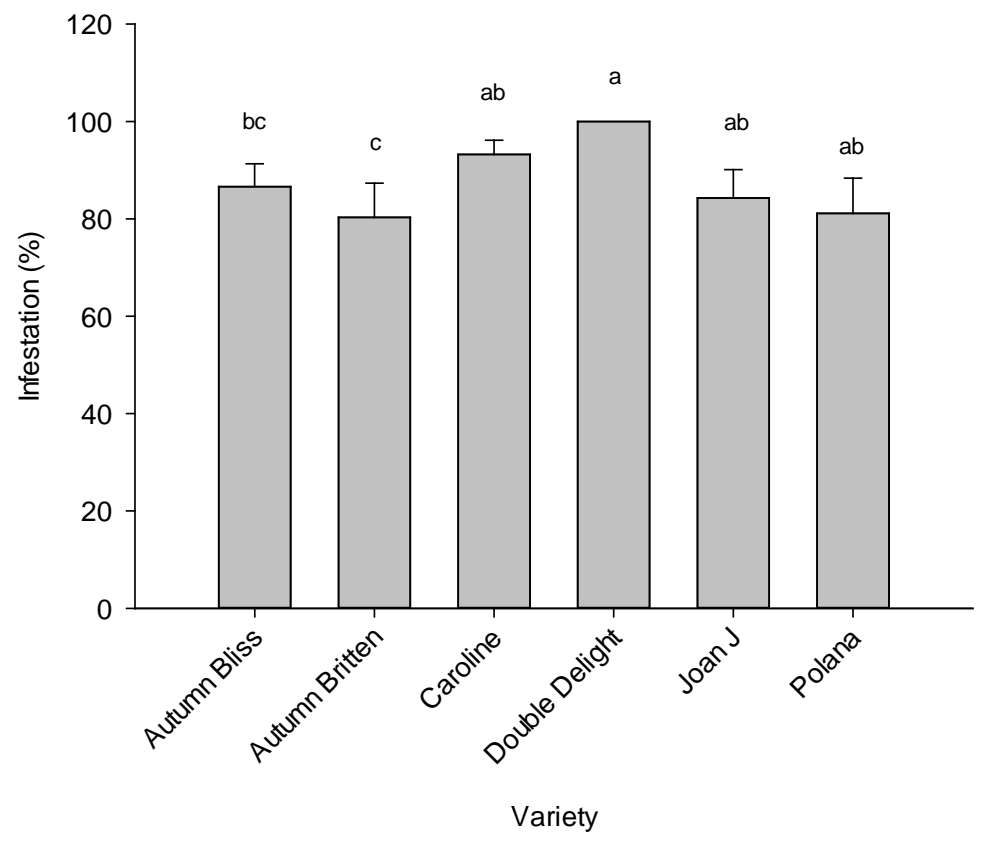

Figure 1. Varieties of Red Primocane-Fruiting raspberries evaluated for spotted-wing drosophila infestations by percent of infested berries in 2014 . 


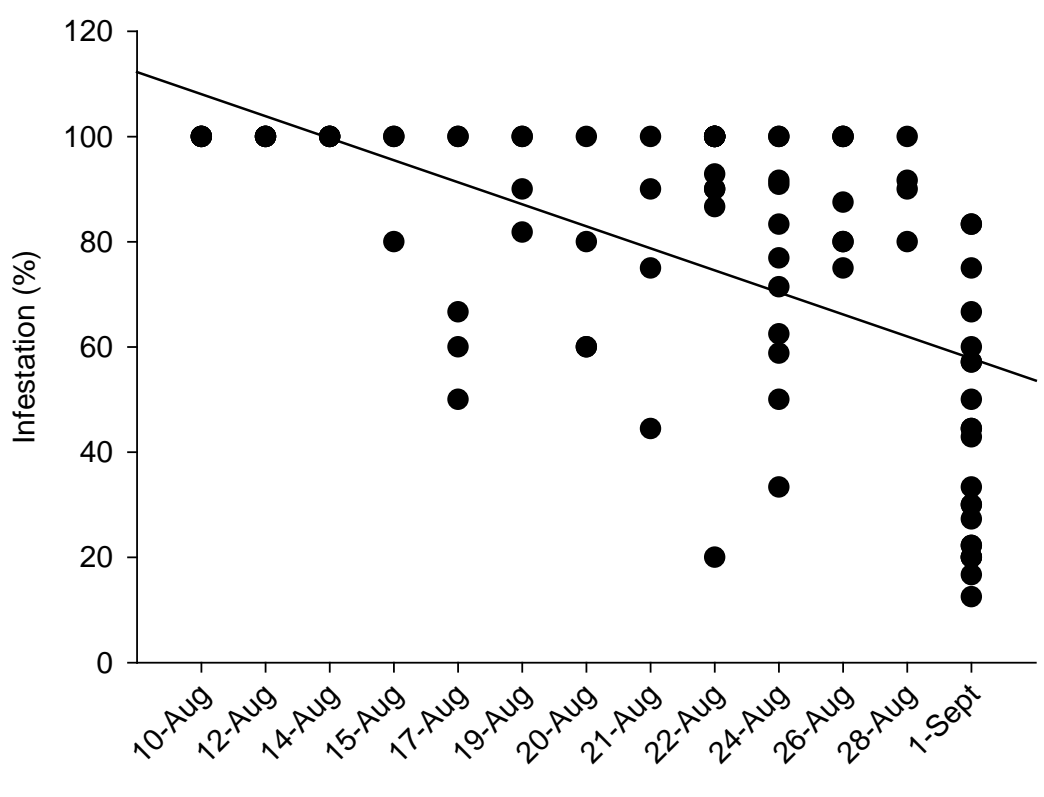

Harvest Date

Figure 2. Regression of percent infested fruit over time for the varieties of Red PrimocaneFruiting raspberries evaluated for spotted-wing drosophila infestations in 2015.

\subsection{Abundance and Damage}

Plant variety also had a significant impact on the average number of larvae per fruit $(\mathrm{F}=10,370=48.81 p<$ 0.0001) (Figure 3); however, we also found that there was a significant impact of sample date $(\mathrm{F}=3,370=$ $2.83 p<0.038)$ as well as an interaction between sample date and variety $(\mathrm{F}=30,370=2.39 p<0.0001)$ (Figure 4). When each sample date was evaluated significant differences were detected between varieties on seven sample dates (Table 2; Figure 4). Finally There was a significant negative correlation between the average number of larvae per fruit and sample $\left(\mathrm{F}=1,412=183.80 p<0.0001 ; \mathrm{r}^{2}=0.31\right)$ with significantly fewer larvae per berry in later samples (Figure 5).

\section{Discussion}

There is no doubt that the host range of SWD is vast [9] [12]-[14] [24]. Nevertheless, D. suzukii appears to exhibit some level of varietal preference within host species, or certain varieties may be more suitable, leading to increased adult populations. However, there may be other factors that are influencing the infestation patterns observed. Consistent with other studies, we found that there are higher levels of infestations in some varieties, and that some varieties produced more larvae [1] [9] [25]. We also observed a significant negative correlation in both of these factors as the harvest season progressed.

Somewhat puzzling was the observed decrease in infested fruit and larvae over time even at a time when the number of adults observed in baited traps was increasing (CRP unpublished data). This trend could indicate dispersal of SWD to neighboring crop hosts or alternative hosts in the environment. One possible explanation for this could be due changes in host that modify a key biological trigger that reduces the olfactory attractiveness of the natal food source. Numerous studies have shown that many different species of insects, including some drosophilids, use olfactory cues to locate and ultimately utilize host plants [19] [26]-[28]. In addition, Different varieties of crops contain differing amounts of resources, such as soluble sugar content (brix) which likely effects varietal preference [9] [19] [28] (Table 1). Slight changes in fruit chemistry can cause greater attractiveness to female SWD, through volatiles released or via better nutrition for developing larvae.

Timing is important when dealing with agricultural pests, and local climactic conditions or microclimates may also influence SWD population dynamics [29]-[31]. Pest development time and the time that susceptible fruit are available play an essential role in the severity of an infestation. In addition to understanding how climate impacts nutritional values and attractiveness of varieties, this information may also be useful in evaluating the 


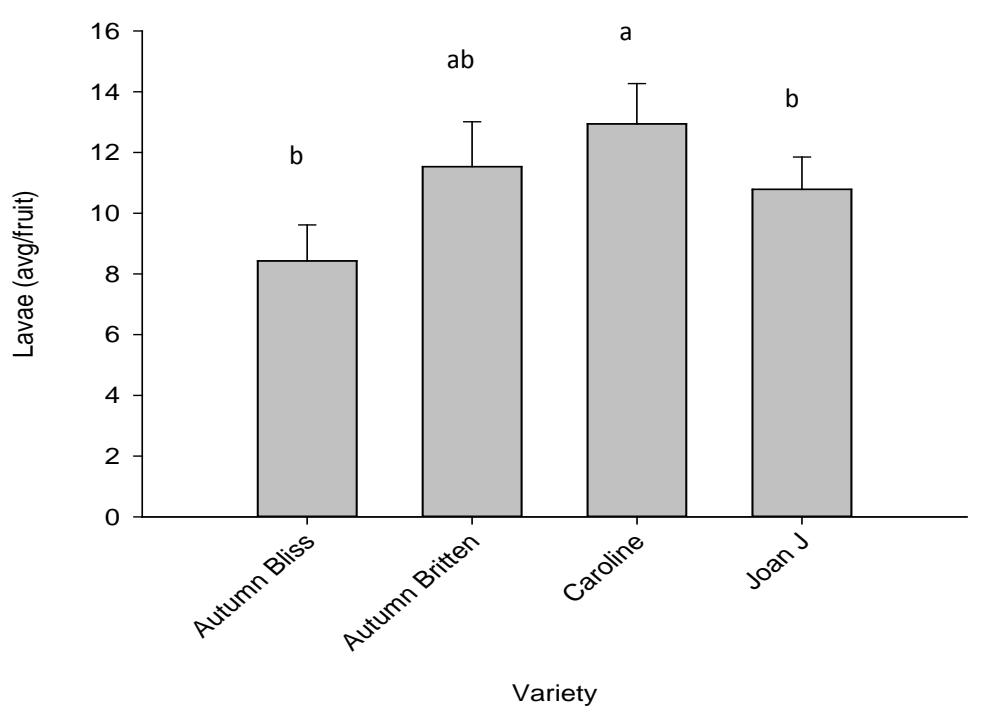

Figure 3. Average larvae per fruit for each variety of Red Primocane-Fruiting raspberries evaluated for spotted-wing drosophila infestations in 2015.

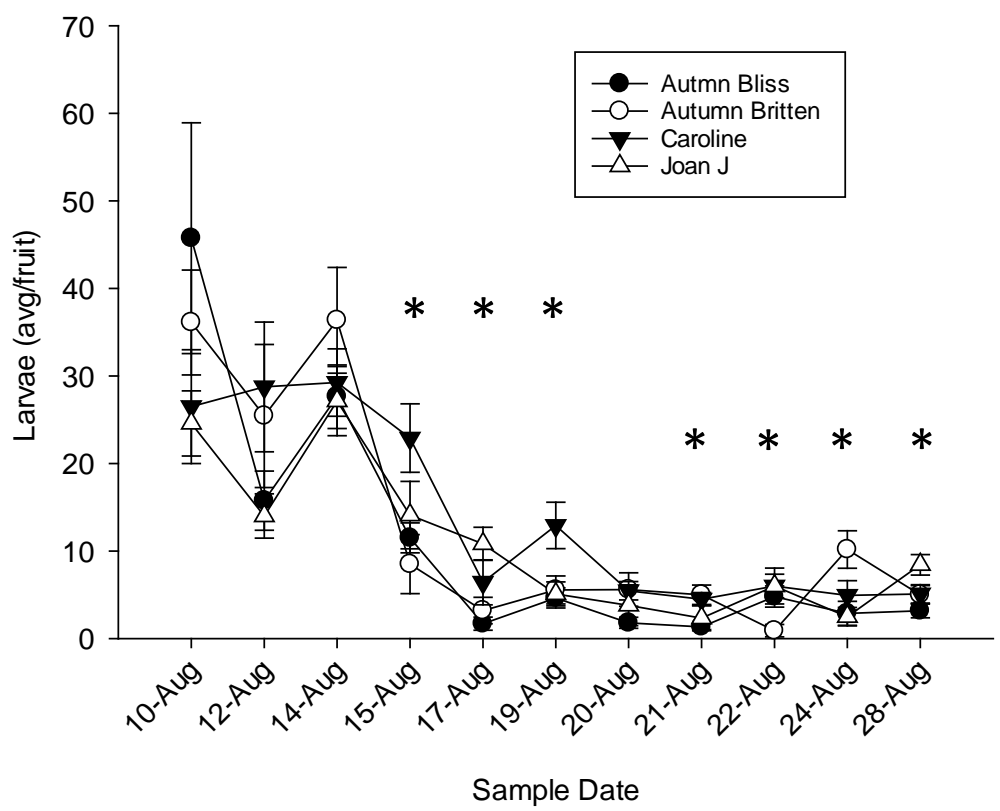

Figure 4. Average number of larvae per fruit over time by varieties of Red Primocane-Fruiting raspberries evaluated for spotted-wing drosophila infestations in 2014 and 2015. Dates marked with an asterisk are significantly different.

Table 2. Varieties of Red Primocane-Fruiting raspberries evaluated for spotted-wing drosophila infestations in 2014 and 2015.

\begin{tabular}{cccccccccccc}
\hline & \multicolumn{10}{c}{ Average Larvae per Fruit } \\
\cline { 2 - 29 }$y$ & 10-Aug & 12-Aug & 14-Aug & 15-Aug & 17-Aug & 19-Aug & 20-Aug & 21-Aug & 22-Aug & 24-Aug & 28-Aug \\
\hline Autumn Bliss & $45.75 \mathrm{a}$ & $15.75 \mathrm{a}$ & $27.63 \mathrm{a}$ & $11.50 \mathrm{ab}$ & $1.70 \mathrm{~b}$ & $4.64 \mathrm{~b}$ & $1.80 \mathrm{a}$ & $1.33 \mathrm{~b}$ & $4.80 \mathrm{ab}$ & $2.88 \mathrm{~b}$ & $3.17 \mathrm{~b}$ \\
Autumn Britten & $36.125 \mathrm{a}$ & $25.43 \mathrm{a}$ & $36.38 \mathrm{a}$ & $8.50 \mathrm{~b}$ & $3.20 \mathrm{~b}$ & $5.55 \mathrm{~b}$ & $5.60 \mathrm{a}$ & $5.00 \mathrm{a}$ & $0.90 \mathrm{~b}$ & $10.17 \mathrm{a}$ & $5.00 \mathrm{ab}$ \\
Caroline & $26.5 \mathrm{a}$ & $28.75 \mathrm{a}$ & $29.25 \mathrm{a}$ & $22.90 \mathrm{a}$ & $6.43 \mathrm{ab}$ & $12.92 \mathrm{a}$ & $5.45 \mathrm{a}$ & $4.50 \mathrm{ab}$ & $6.00 \mathrm{a}$ & $4.92 \mathrm{ab}$ & $5.10 \mathrm{ab}$ \\
Joan J & $24.57 \mathrm{a}$ & $14.00 \mathrm{a}$ & $27.13 \mathrm{a}$ & $14.10 \mathrm{ab}$ & $10.82 \mathrm{a}$ & $5.10 \mathrm{~b}$ & $3.80 \mathrm{a}$ & $2.33 \mathrm{ab}$ & $6.00 \mathrm{ab}$ & $2.50 \mathrm{~b}$ & $8.43 \mathrm{a}$ \\
p-value & 0.21 & 0.21 & 0.45 & 0.02 & 0.002 & 0.007 & 0.18 & 0.02 & 0.02 & 0.02 & 0.005 \\
\hline
\end{tabular}




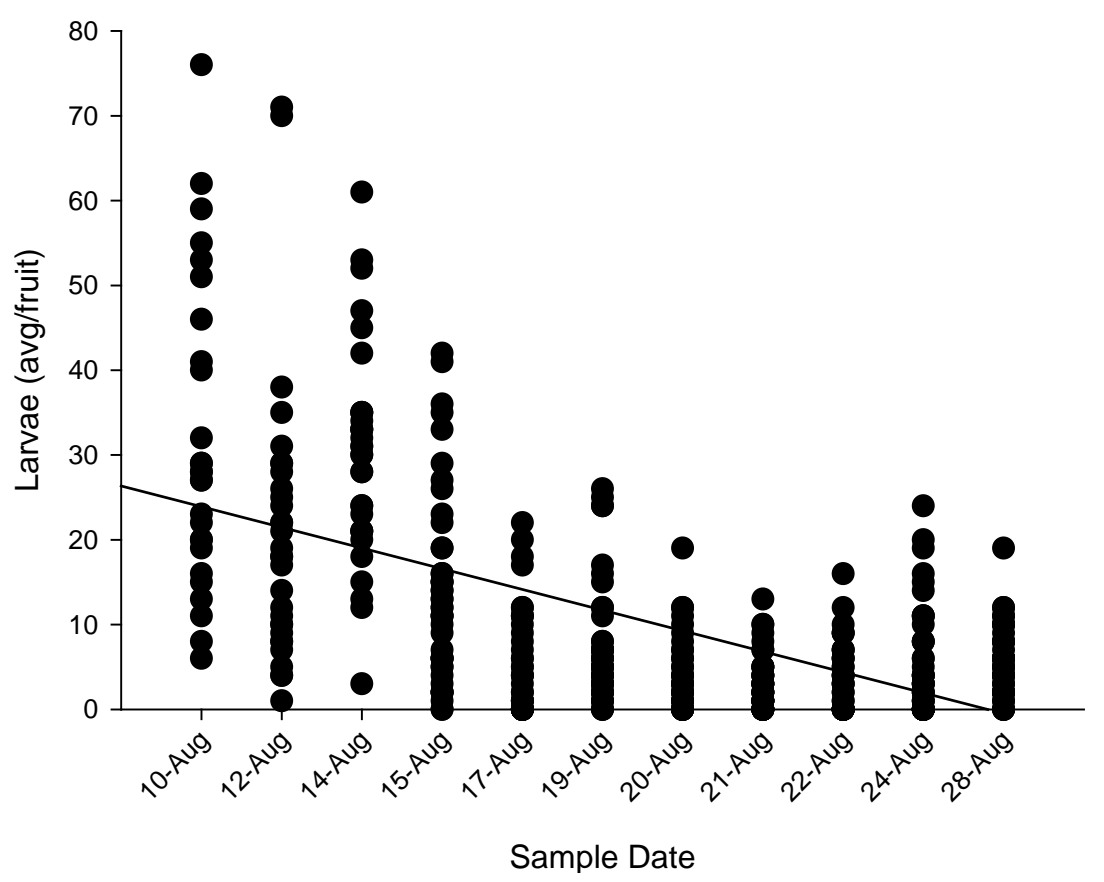

Figure 5. Regression of the average number per berry over time for the varieties of Red Primocane-Fruiting raspberries evaluated for spotted-wing drosophila infestations in 2015.

potential to provide a phenological mismatch between host and pest. Further exploration into varietal susceptibility is needed to determine what characteristic might make varieties more or less susceptible to SWD infestations.

What remains to be determined is what constitutes optimal development for SWD. Previous assumptions describe fitness for SWD as larger, heavier individuals, faster development time, and greater numbers of eggs laid. It has not been thoroughly explored if fitness truly is defined by those parameters. For example, greater egg numbers may not be the more fit option if few of them survive. The varietal differences observed though fits with the ecological concept of ideal free distribution [32] [33]. A less optimal environment may be selected by the adult female if the competition in the more optimal environment yields detrimental characteristics (such as competition) to the survival of offspring. Changes in host preference and decreasing larval populations, while trap populations increase (CRP unpublished data), support this idea. As yet, the ideal free distribution has not been explored nor discussed in previous research as it relates to SWD. Future studies should focus on evaluating ideal free distribution for SWD including: determining impacts of host plant and variety on fitness, the effects of competition on fitness, and the combination of these two factors.

\section{Conclusions}

Currently the greatest focus for research and extension efforts on SWD has been about the identification of effective insecticides. The majority of these compounds are broad-spectrum insecticides. As growers continue to rely on pesticides for control, this will undoubtedly lead to unintended environmental and ecological consequences resulting in the development of insecticides resistance issues.

Unfortunately, there is a tremendous lack of information on the biology and management of many invasive pests. Successful IPM is dependent on understanding where and when pests occur before taking action. However, a major challenge with invasive species such as SWD is our lack of fundamental knowledge about their biology, and ecology, which is critical in refining adequate implementation of effective monitoring and management practices.

The results of this project allow us to begin to identify mechanisms of varietal susceptibility and plant-insect phenology, through which we can provide berry producers with methods to continue sustainable production and maintain profitability. Selecting varieties that provide a phenological mismatch with key pests is an environmentally-sound approach, providing farmers with a significant and sustainable improvement over the frequent 
use of insecticide applications currently recommended. Broadening our understanding of these fundamental knowledge gaps is critical to implementing and refining sufficient and effective monitoring and management practices for this pest.

One of the keys to development of an IPM program for SWD remains understanding host preference and varietal susceptibility of preferred host crops. For cold hardy raspberries, it is clear that there is a varietal preference occurring. Understanding the host selection and varietal preference opens the door to further understand the biology and ecology of this pest. Key questions remain unanswered, but additional studies can add to our understanding of where and when outbreaks and infestations will occur which will ultimately allow a more integrated approach in managing SWD.

\section{Acknowledgements}

This study was conducted with the support of Dan Braaten, Chuck Heggedahl, Doug Hendrickson, Derek Leppanen, Bob Smith, Keith Mann, Joe Benes and Rob Nalder at the North Central Research as well as the entomology and wild rice summer field crew. This research was partially funding by the University of Minnesota Rapid agricultural response fund.

\section{References}

[1] Lee, J.C., Bruck, D.J., Curry, H., Edwards, D.L., Haviland, D.R., Van Steenwyk, R. and Yorgey, B. (2011) The Susceptibility of Small Fruits and Cherries to the Spotted Wing Drosophila, Drosophila suzukii. Pest Management Science, 67, 1358-1367. http://dx.doi.org/10.1002/ps.2225

[2] Calabria, G., Máca, J., Bachli, G., Serra, L. and Pascual. M. (2012) First Records of the Potential Pest Species Drosophila suzukii (Diptera: Drosophilidae) in Europe. Journal of Applied Entomology, 136, 139-147.

[3] Deprá, M., Poppe, J.L., Schmitz, H.J., De Toni, D.C. and Valente, V.L. (2014) The First Records of the Invasive Pest Drosophila suzukii in the South American Continent. Journal of Pest Science, 87,379-383.

[4] Kinjo, H., Kunimi, Y. and Nakai, M. (2014) Effects of Temperature on the Reproduction and Development of Drosophila suzukii (Diptera: Drosophilidae). Applied Entomology and Zoology, 49, 297-304. http://dx.doi.org/10.1007/s13355-014-0249-z

[5] Asplen, M.K., Anfora, G., Biondi, G., Choi, D.S., Chu, D., Daane, K.M., Gibert, P., Gutierrez, A.P., Hoelmer, K.A., Hutchison, W.D., Isaacs, R., Jiang, Z.L., Kárpáti, Z.L., Kimura, M.T., Pascual, M., Philips, C.R., Plantamp, C., Ponti, L., Vétek, L., Vogt, H., Walton, V.M., Yu, Y., Zappalà, L. and Desneux, N. (2015) Invasion Biology of Spotted Wing Drosophila (Drosophila suzukii): A Global Perspective and Future Priorities. Journal of Pest Science, 88, 469-494. http://dx.doi.org/10.1007/s10340-015-0681-z

[6] Bolda, M., Goodhue, R. and Zalom, F.G. (2010) Spotted Wing Drosophila: Potential Economic Impact of a Newly Established Pest. Giannini Foundation of Agricultural Economics, University of California, Berkley, CA, Vol. 13, 5-8.

[7] Walsh, D.B., Bolda, M.P., Goodhue, R.E., Dreves, A.J., Lee, J, Bruck, D.J., Walton, V.M., O’Neal, S.D. and Zalom, F.G. (2011) Drosophila suzukii (Diptera: Drosophilidae): Invasive Pest of Ripening Soft Fruit Expanding Its Geographic Range and Damage Potential. Journal of Integrated Pest Management, 2, G1-G7. http://dx.doi.org/10.1603/IPM10010

[8] Burrack, H.J., Smith, J.P., Pfeiffer, D., Koehler, G. and LaForest, J. (2012) Using Volunteer-Base Networks to Track Drosophila suzukii (Diptera: Drosophilidae) an Invasive Pest of Fruit Crops. Journal of Integrated Pest Management, 3, B1-B5. http://dx.doi.org/10.1603/IPM12012

[9] Burrack, H.J., Fernandez, G.E., Spivey, T. and Kraus, D.A. (2013) Variation in Selection and Utilization of Host Crops in the Field and Laboratory by Drosophila suzukii Matsumara (Diptera: Drosophilidae), an invasive Frugivore. Pest Management Science, 69, 1173-1180. http://dx.doi.org/10.1002/ps.3489

[10] Bellamy, D.E., Sisterson, M.S. and Walse, S.S. (2013) Quantifying Host Potentials: Indexing Postharvest Fresh Fruits for Spotted Wing Drosophila, Drosophila suzukii. PLoS ONE, 8, e61227. http://dx.doi.org/10.1371/journal.pone.0061227

[11] Kanzawa, T. (1939) Studies on Drosophila suzukii Mats. Kofu. Review of Applied Entomology, 29, 622.

[12] Kimura, M.T., Toda, M.J., Beppu, K. and Watabe, H. (1977) Breeding Sites of Drosophilid Files in and Near Sapporo, Nomherrr Japan, with Supplementary Notes on Adult Feeding Habits. Kontyû, 45, S71-S82,

[13] Nishiharu, S. (1980) A Study of Ecology and Evolution of Drosophilid Files with Special Regard to Imaginal and Larval Feeding Habits and Seasonal Population Fluctuations. Doctor of Science Thesis, Tokyo Metropolitart University, Tokyo. 
[14] Mitsui, H., Beppu, K. and Kimura, M.T. (2010) Seasonal Life Cycles and Resource Uses of Flower- and Fruit-Feeding Drosophilid Flies (Diptera: Drosophilidae) in Central Japan. Entomological Science, 13, 60-67. http://dx.doi.org/10.1111/j.1479-8298.2010.00372.x

[15] Steffan, S.A., Lee, J.C., Singleton, M.E., Vilaire, A., Walsh, D.B., Lavine, L.S. and Pattern, K. (2013) Susceptibility of Cranberries to Drosophila suzukii (Diptera: Drosophilidae). Journal of Economic Entomology, 106, 2424-2427. http://dx.doi.org/10.1603/ec13331

[16] Gutierrez, A.P. and Ponti, L. (2013) Eradication of Invasive Species: Why the Biology Matters. Environmental Entomology, 42, 395-411. http://dx.doi.org/10.1603/EN12018

[17] Kimura, M.T. (2004) Cold and Heat Tolerance of Drosophilid Flies with Reference to Their Latitudinal Distributions. Oecologia, 140, 442-449. http://dx.doi.org/10.1007/s00442-004-1605-4

[18] Shearer, P., West, J., Walton, V., Brown, P., Svetec, N. and Chiu, J. (2016) Seasonal Cues Induce Phenotypic Plasticity of Drosophila suzukii to Enhance Winter Survival. BMC Ecology, 16, 11. http://dx.doi.org/10.1186/s12898-016-0070-3

[19] Diepenbrock, L.M., Swoboda-Bhattarai, K.A. and Burrack, H.J. (2016) Ovipositional Preference, Fidelity, and Fitness of Drosophila suzukii in a Co-Occurring Crop and Non-Crop Host System. Journal of Pest Science, 1-9.

[20] Haviland, D.R., Caprile, J., Rill, S., Hamby, K.A. and Grant, J.A. (2014) Varies by Season, Crop and Nearby Vegetation. California Agriculture, 70, 24-31. http://dx.doi.org/10.3733/ca.v070n01p24

[21] Klick, J., Yang, W.Q., Walton, V.M., Dalton, D.T., Hagler, J.R., Dreves, A.J., Lee, J.C. and Bruck, D.J. (2016) Distribution and Activity of Drosophila suzukii in Cultivated Raspberry and Surrounding Vegetation. Journal of Applied Entomology, 140, 37-46. http://dx.doi.org/10.1111/jen.12234

[22] Dreves, A.J., Cave, A. and Lee, J. (2014) A Detailed Guide for Testing Fruit for the Presence of Spotted Wing Drosophila (SWD) Larvae. OSU Extension Publication, Corvallis, OR.

[23] SAS Institute Inc. (2013) Using JMP 11. SAS Institute Inc., Cary.

[24] Lee, J.C., Dreves, A.J., Cave, A.M., Kawai, S., Isaacs, R., Miller, C., Van Timmeren, S. and Bruck, D.J. (2015) Infestation of Wild and Ornamental Noncrop Fruits by Drosophila suzukii (Diptera: Drosophilidae). Annals of the Entomological Society of America, 108, 117-129. http://dx.doi.org/10.1093/aesa/sau014

[25] Kinjo, H., Kuimi, Y., Ban, T. and Nakai, M. (2013) Oviposition Efficacy of Drosopihla suzukii (Diptera: Drosophilidae) on Different Cultivars of Blueberry. Horticultural Entomology, 106, 1767-1771.

[26] Hoffman, A.A. (1985) Interspecific Variation in the Response of Drosophila to Chemicals and Fruit Odors in a Wind Tunnel. Australian Journal of Zoology, 33, 451-460. http://dx.doi.org/10.1071/ZO9850451

[27] Keesey, I.W., Knaden, M. and Hansson, B.S. (2015) Olfactory Specialization in Drosophila suzukiisupports an Ecological Shift in Host Preference from Rotten to Fresh Fruit. Journal of Chemical Ecology, 41, 121-128. http://dx.doi.org/10.1007/s10886-015-0544-3

[28] Yu, D., Zalom, F.G. and Hamby, K.A. (2013) Host Status and Fruit Odor Response of Drosophila suzukii (Diptera: Drosophilidae) to Figs and Mulberries. Journal of Economic Entomology, 106, 1932-1937. http://dx.doi.org/10.1603/EC12480

[29] Tochen, S., Dalton, D.T., Wiman, N.G., Hamm, C., Shearer, P.W. and Walton, V.M. (2014) Temperature-Related Development and Population Parameters for Drosophila suzukii (Diptera: Drosophilidae) on Cherry and Blueberry. Environmental Entomology, 43, 501-510. http://dx.doi.org/10.1603/EN13200

[30] Rogers, M.A., Burkness, E.C. and Hutchison, W.D. (2015) Evaluation of Covered Tunnels for Management of Drosophila suzukii in Fall-Bearing Red Raspberries: Potential for Reducing Insecticide Use. Journal of Pest Science, 1-7.

[31] Wiman, N.G., Dalton, D.T., Anfora, G., Biondi, A., Chiu, J.C., Daane, K.M., Gerdeman, B., Gottardello, A., Hamby, K.A., Isaacs, R., Grassi, A., Ioriatti, C., Lee, J.C., Miller, B., Rossi Stacconi, V., Shearer, P.W., Tanigoshi, L., Wang, X. and Walton, V.M. (2016) Drosophila suzukii Population Response to the Environment and Management Strategies. Journal of Pest Science, 1-13. http://dx.doi.org/10.1007/s10340-016-0757-4

[32] Fretwell, S.D. (1972) Populations in a Seasonal Environment. Princeton University Press, Princeton

[33] Fretwell, S.D. and Lucas, H.L. (1970) On Territorial Behaviour and Other Factors Influencing Habitat Distribution in Birds. I. Theoretical Development. Acta Biotheoretica, 19, 16-36. http://dx.doi.org/10.1007/BF01601953 


\section{Submit or recommend next manuscript to SCIRP and we will provide best service for you:}

Accepting pre-submission inquiries through Email, Facebook, LinkedIn, Twitter, etc.

A wide selection of journals (inclusive of 9 subjects, more than 200 journals)

Providing 24-hour high-quality service

User-friendly online submission system

Fair and swift peer-review system

Efficient typesetting and proofreading procedure

Display of the result of downloads and visits, as well as the number of cited articles

Maximum dissemination of your research work

Submit your manuscript at: http://papersubmission.scirp.org/ 